\title{
Corrupção e participação política no Brasil: diagnósticos e consequências
}

Corruption and political participation:

diagnosis and consequences

Qual seria a relação entre a experiência com atos corruptos e o envolvimento em atividades participativas dos brasileiros? Essa é a questão que norteia o trabalho. Apesar de a literatura politóloga dedicar-se, apenas de forma marginal, à compreensão desse tipo de relação, entendemos que há indícios que apontam quase que exclusivamente para efeitos deletérios da corrupção no engajamento cívico. Como desenvolveremos adequadamente mais à frente, Hirschman (1983), por exemplo, considera que a decepção é o principal fator para o desengajamento político e que esta é causada pela percepção do alastramento da corrupção entre os agentes públicos. A corrupção funcionaria como um gatilho para a desafeição para com a política. Warren (2012), por sua vez, associa a corrupção à corrosão do caráter democrático, com consequência grave para o estoque de legitimidade do regime e para o interesse dos cidadãos no ativismo político. Em contextos claramente percebidos pelos indivíduos como dominados pela corrupção, a confiança esvai-se e, com ela, o engajamento psicológico necessário à participação (Verba, Schlozman e Brady, 1995).

Apesar de alguns autores funcionalistas, como Huntington (1968), defenderem a possibilidade de efeitos positivos da

É professor de ciência política na Universidade Federal de Goiás (UFG).E-mail: <rbonisilva@gmail.com>.

2 É professor de ciência política na Universidade Estadual de Maringá (UEM) e no Programa de Pós-Graduação em Ciência Política da Universidade Federal do Paraná (UFPR). E-mail: $<$ ednaldoribeiro@icloud.com>. 
corrupção em contextos ditatoriais, por considerá-la um meio de superar as normas tradicionais e os regulamentos burocráticos que emperram o desenvolvimento econômico, sob o ponto de vista do comportamento cívico, não é fácil localizar na literatura especializada a formulação de possíveis efeitos positivos da corrupção. Como exemplo, Doig e McIvor (1999) e Doig e Theobald (2000) sugerem que a alta taxa de percepção de corrupção relaciona-se ao baixo nível de confiança institucional, componente pouco favorável à estabilidade do sistema político. Seligson (2002), por sua vez, identifica, entre os experientes com atos corruptos, os mais baixos níveis de apoio ao regime político democrático, assim como os mais baixos níveis de confiança interpessoal.

Objetivamos contribuir para o debate, investigando a relação entre um indicador de corrupção de nível individual - a experiência dos cidadãos com situações de pedido de propina por parte de algum agente público - e diversas modalidades de participação política. Desse modo, podemos analisar se a corrupção apresenta efeitos positivos ou negativos para o engajamento político no contexto brasileiro. Utilizamos como fonte exclusiva de dados o Barômetro das Américas, rodadas de 2007, 2008, 2010 e 2012. ${ }^{3}$

Organizamos o trabalho da seguinte maneira: a seguir debatemos o conceito de participação política, propomos indicadores e analisamos a sua multidimensionalidade. Posteriormente, tratamos das concepções de corrupção, descrevemos dados sobre o indicador e discutimos as contribuições da literatura especializada na relação entre corrupção e orientações políticas (atitudes e comportamento). A partir desses desenvolvimentos, construímos hipóteses e fazemos as análises empíricas relativas à relação entre corrupção e participação política e à propensão à permissividade com corrupção entre os perfis sociais construídos. Ao final, fazemos breves considerações sobre virtudes e limitações dos resultados alcançados.

3 Agradecemos ao Latin American Public Opinion Project (Lapop) e a seus principais apoiadores - United States Agency for International Development (Usaid), Banco Interamericano de Desenvolvimento (BID) e Vanderbilt University - por tornar os dados disponíveis. 


\section{Participação política: definição, indicadores e tipologia}

O debate sobre a participação política é polissêmico e extenso. Há, por exemplo, diversas visões acerca do ambiente em que o fenômeno desenvolve-se e a sua dimensionalidade, além do repertório das atividades participativas. Brady (1999) e Borba (2012) fazem adequados diagnósticos do debate e destacam que um dos poucos pontos consensuais é a consideração de que a participação é um comportamento, uma ação, e não uma atitude, que é algo imbuído de caráter subjetivo.

Consideramos que a participação política refere-se a atividades exercidas por cidadãos, em diversas arenas, que objetivam influenciar as dinâmicas de poder. Logo, entendemos que participar significa tomar parte em algo (Fialho, 2008), que o fenômeno expressa-se por atividades e que pode se desenvolver em diversas arenas, buscando, de forma conflitiva ou cooperativa, influenciar a distribuição de poder (Reis, 2000).

A partir dessa definição, é possível selecionar os indicadores empíricos, presentes no quadro 1 . Antes, porém, devem ser feitas duas considerações. A primeira refere-se ao alcance da dinâmica participativa. Temos uma visão limitada a respeito, não incorporando a concepção de que os seus resultados podem contribuir para uma mudança estrutural do Estado (Pizzorno, 1975). Isso se dá porque a ocorrência de movimentos revolucionários mostra-se pouco frequente ao longo da história, e o que buscamos estudar são os movimentos mais usuais.

A segunda consideração recai sobre o associativismo. É recorrente, em estudos da área, considerar a associação e a filiação a grupos e a movimentos como expressão de participação política. Isso faz sentido, já que um dos caminhos mais comuns para vocalizar preferências e demandas dá-se por essa via. No entanto, é importante ter parcimônia na seleção destes grupos e movimentos. Grupos de igreja, de mulheres ou grêmios recreativos, por exemplo, podem ou não ter relação com questões políticas. O modo como essas variáveis estão descritas no questionário do Barômetro das Américas não possibilita a interpretação de que o engajamento 
a estes grupos está atrelado a questões políticas. Logo, por não possuírem um caráter político inequívoco, elas não são incluídas na lista de indicadores de participação.

\section{Quadro 1 - Indicadores de participação política}

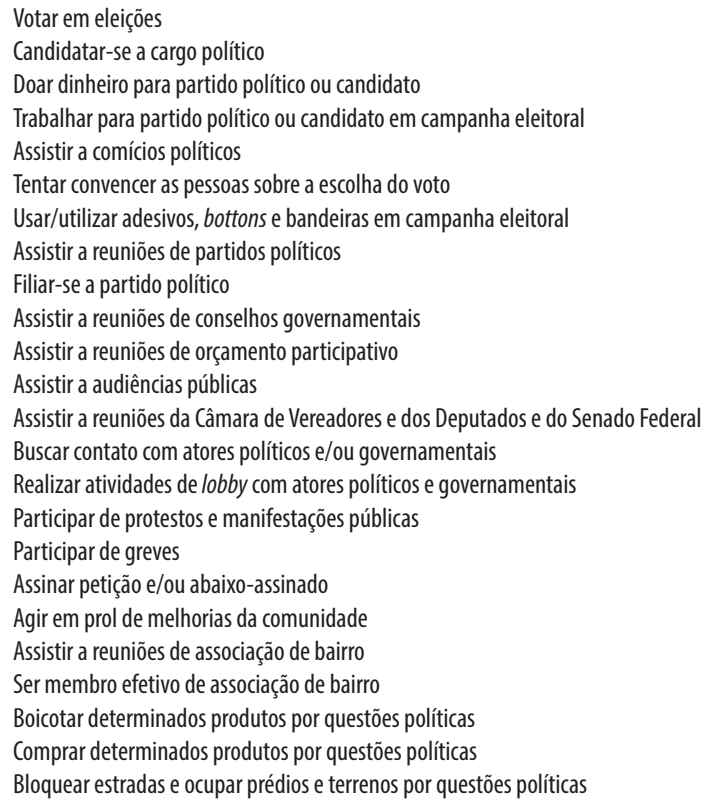

Fonte: elaboração própria

Elaboração própria.

Nem todos esses indicadores estão presentes no banco de dados do Barômetro das Américas, sendo possível trabalharmos somente com 11 variáveis, descritas a seguir:

1) Trabalhar em campanha eleitoral.

2) Contatar deputados (estaduais e federais).

3) Contatar atores políticos governamentais (ministérios e secretarias).

4) Contatar atores políticos locais (prefeitos e autoridades militares).

5) Contatar vereadores e atores governamentais locais. 
6) Agir para solução de problemas na comunidade em que se vive.

7) Assistir a reuniões de associação de bairro.

8) Assistir a reuniões de partido político.

9) Tentar convencer outros sobre a escolha do voto.

10) Participar de manifestações ou protestos públicos.

11) Assinar petições. ${ }^{4}$

O voto não está incluído no trabalho porque, apesar de entendermos o ato como participativo, em Bonifácio e Paulino (2015), há indicações de que os fatores explicativos do comparecimento eleitoral relacionam-se de forma substancialmente diferente das demais modalidades de participação política, sendo sugerida uma investigação específica para essa questão.

Embora haja critérios de ordem teórica para sustentar que todas as variáveis elencadas anteriormente são indicadoras de participação política, realizamos um tratamento empírico a respeito para averiguar se estas variáveis agrupam-se em uma única dimensão ou se podem ser discriminadas em diferentes tipos ou modalidades, assumindo um caráter multidimensional. Esse aspecto da participação política é investigado por diversos autores, sendo usual a utilização do teste de análise fatorial exploratória. ${ }^{5}$

$\mathrm{Na}$ tabela 1, as colunas representam os resultados da análise fatorial exploratória para cada rodada de dados do Barômetro das Américas e as linhas comportam as atividades participativas. As cargas fatoriais em cada célula gerada pelo cruzamento de linhas e colunas indicam o maior valor para cada variável. Para as rodadas de 2007, 2008 e 2010, foram gerados três fatores, e para a rodada de 2012, quatro.

As quatro primeiras variáveis mostram-se agrupadas em um mesmo fator em todas as rodadas e são indicadoras de contato com atores políticos e governamentais. Essa modalidade de participação

4 As variáveis são codificadas no questionário do Barômetro das Américas da seguinte maneira, respectivamente: CP2, CP4a, CP4, NP2, CP5, CP8, CP13, PP1, PROT1 (2007 e 2008)/PROT3 (2010 e 2012) e PROT6.

5 Originalmente, esse procedimento parte de uma matriz de correlação de Pearson, adequada quando as variáveis apresentam natureza contínua (Gorsuch, 1983). A solução foi aplicar uma correção policórica, ideal para manipular dados binários e categóricos nesse teste (Drasgow, 1998). 
que se caracteriza pelo contato direto entre representante(s) e representado(s), sem a presença de manifestações ou atos contestatórios, ou seja, de atividades que objetivam exercer pressão pública. Com base na redação das variáveis no questionário, não é possível saber se o contato ocorre de forma individual ou coletiva e tampouco a natureza das questões tratadas (se envolvem demandas legais ou criminosas). ${ }^{6}$

As atividades de "ação em prol da comunidade" e "assistir reunião de associação de bairro" são constitutivas do ativismo comunitário, que denota atuação em questões políticas de abrangência exclusivamente local, que visam influenciar políticas e atores que cuidam de problemas da comunidade em que se vive. As maiores cargas estatísticas destes indicadores mostram-se agrupadas em um único fator nas três primeiras rodadas, havendo uma distorção desse padrão em 2012.

O terceiro conjunto de variáveis - "trabalho em campanha eleitoral", "convencer os outros sobre a escolha do voto" e "participação em reuniões de partidos e movimentos políticos" - compõe a modalidade ativismo partidário e eleitoral, que se caracteriza pela tentativa de influenciar resultados eleitorais e por estar circunscrita a instituições e eventos oficiais. A formulação da variável sobre participação em reuniões de partidos e de movimentos políticos apresenta problemas, pois nos priva de distinguir o envolvimento dos brasileiros em cada uma dessas duas diferentes instituições. Os resultados destacados a seguir refletem esse problema de formulação: a variável compõe o fator sobre atividades partidárias e eleitorais nas rodadas de 2007 e 2012, mas também o fator de ativismo comunitário, nos anos de 2008 e 2010. Seguimos as indicações de estudos da área, como os de Verba, Nie e Kim (1987), Booth e Seligson (2009) e Bonifácio e Paulino (2015), que, em diferentes anos e contextos, arrolaram indicadores similares como relacionados ao ativismo partidário e eleitoral.

6 Para mais detalhes, conferir a redação das variáveis CP2 CP4, CP4a e CP5 no questionário do Barômetro das Américas. 
Por fim, as pesquisas utilizadas contêm uma única pergunta genérica sobre o envolvimento dos cidadãos em atividades participativas contestatórias, o engajamento em protestos. Essa variável não se agrupa de forma satisfatória em nenhum dos fatores gerados, apresentando sempre baixo valor de carga estatística. Contudo, na rodada de 2012, é incorporada à variável sobre assinatura de petições e abaixo-assinados, que se agrupa com a variável indicadora de participação em protestos em um fator à parte dos demais, com altas cargas estatísticas, constituindo, assim, uma modalidade específica de participação, intitulada ativismo de protesto.

Esses resultados fortalecem ainda mais os achados de estudos como os de Verba, Nie e Kim (1987), Norris (2002), Booth e Seligson (2009) e Teorell, Torcal e Montero (2007), que asseveram a natureza multidimensional da participação política. Diante de tantas evidências sobre as diferentes modalidades ou tipos de participação política, consideramos inadequado concebê-la como um fenômeno uno, restrito ao ambiente governamental e eleitoral, como entende Milbrath (1965). O quadro 2 apresenta o nome da cada modalidade de participação política encontrado por meio da análise fatorial, assim como os seus indicadores.

Quadro 2 - Modalidades de participação política e seus indicadores

1) Ativismo comunitário: assistir a reuniões de associação de bairro e agir em prol de melhorias na comunidade.

2) Contato com atores políticos e governamentais: contato com deputado estadual e federal, com ator político local, com ator governamental e com vereador e atores governamentais locais.

3) Ativismo partidário e eleitoral: trabalho em campanha eleitoral, assistir a reuniões de partido político, tentar convencer os outros sobre a escolha do voto.

4) Ativismo de protesto: participação em manifestações e protestos e assinatura de abaixo-assinado e petição.

Elaboração própria. 
Tabela 1 - Análise fatorial exploratória com as variáveis sobre participação política

\begin{tabular}{|c|c|c|c|c|c|c|c|c|c|c|c|c|c|}
\hline & \multicolumn{3}{|c|}{2007} & \multicolumn{3}{|c|}{2008} & \multicolumn{3}{|c|}{2010} & \multicolumn{4}{|c|}{2012} \\
\hline & 1 & 2 & 3 & 1 & 2 & 3 & 1 & 2 & 3 & 1 & 2 & 3 & 4 \\
\hline Contato com deputados & 0.822 & - & - & 0.698 & - & - & 0.565 & - & - & 0.758 & - & - & - \\
\hline $\begin{array}{l}\text { Contato com atores } \\
\text { governamentais }\end{array}$ & 0.712 & - & - & 0.623 & - & - & 0.504 & - & - & 0.716 & - & - & - \\
\hline $\begin{array}{l}\text { Contato com atores } \\
\text { políticos locais }\end{array}$ & 0.860 & - & - & 0.886 & - & - & 0.859 & - & - & 0.911 & - & - & - \\
\hline Contato com vereadores & 0.679 & - & - & 0.799 & - & - & 0.830 & - & - & 0.893 & - & - & - \\
\hline $\begin{array}{l}\text { Ação em prol da } \\
\text { comunidade }\end{array}$ & - & - & 0.367 & - & 0.522 & - & - & 0.518 & - & 0.316 & - & - & - \\
\hline $\begin{array}{l}\text { Assistir à reunião de } \\
\text { associação de bairro }\end{array}$ & - & - & 0.540 & - & 0.593 & - & - & 0.673 & - & - & - & - & 0.383 \\
\hline $\begin{array}{c}\text { Trabalho em } \\
\text { campanha eleitoral }\end{array}$ & - & 0.696 & - & - & - & 0.632 & - & - & 0.494 & - & 0.570 & - & - \\
\hline $\begin{array}{l}\text { Assistir à reunião de } \\
\text { partidos políticos e } \\
\text { movimentos políticos }\end{array}$ & - & 0.727 & - & - & 0.426 & - & - & 0.595 & - & - & 0.579 & - & - \\
\hline $\begin{array}{l}\text { Convencer os outros } \\
\text { sobre a escolha do voto }\end{array}$ & - & 0.574 & - & - & - & 0.551 & - & - & 0.492 & - & 0.540 & - & - \\
\hline Participar de protestos & - & 0.312 & - & - & - & - & - & 0.347 & - & - & - & 0.672 & - \\
\hline $\begin{array}{l}\text { Assinar petições e } \\
\text { abaixo-assinados }\end{array}$ & - & - & - & - & - & - & - & - & - & - & - & 0.696 & - \\
\hline KMO & & 0.805 & & & 0.719 & & & 0.749 & & & & 709 & \\
\hline Alpha de Cronbach & & 0.611 & & & 0.524 & & & 0.533 & & & & 589 & \\
\hline
\end{tabular}

Fonte: Dados do Barômetro das Américas, de autoria de Latin American Public Opinion Project (Lapop), disponível em: <www. LapopSurveys.org>.

Elaboração própria.

A tabela 2 apresenta o percentual de ativismo para cada modalidade de participação política, considerando todas as rodadas de dados. ${ }^{7}$ Apesar da considerável flutuação nos percentuais, podemos

7 A seguir, os códigos das variáveis que constituem os índices presentes na tabela 2 e as respectivas categorias que indicam participação: PP2, CP2, CP4, CP4a, CP5 (rodada de 2007), NP2, PROT3 e PROT6: "Sim"/CP5 (rodadas de 2008, 2010 e 2012), CP8 e CP13: "uma vez por semana", "uma ou duas vezes por mês" ou "uma ou duas vezes por ano"/PP1: "frequentemente", "de vez em quando" ou "muito raramente"/PROT1 (rodadas de 2007 e 2008): "algumas vezes" ou "quase nunca". 


\section{afirmar que a maior parte dos brasileiros não participa de quaisquer atividades relacionadas às quatro modalidades. Ademais, o percen- tual de cidadãos participativos decai de forma linear à medida que aumenta a quantidade de atividades participativas realizadas. ${ }^{8}$}

\section{Tabela 2 - Frequência de participação política por modalidade, de 2007 a 2012 (\%)}

\begin{tabular}{|c|c|c|c|c|c|c|}
\hline \multirow{2}{*}{ Modalidades de participação política } & \multicolumn{6}{|c|}{ Nível de participação } \\
\hline & 0 & 1 & 2 & 3 & 4 & Total de participação \\
\hline \multicolumn{7}{|c|}{2007} \\
\hline Ativismo comunitário & 64,7 & 26,9 & 8,4 & - & - & 35,3 \\
\hline Ativismo partidário e eleitoral & 55,3 & 32,0 & 9,8 & 2,9 & & 44,7 \\
\hline Contato com atores políticos e governamentais & 73,6 & 14,6 & 6,7 & 3,9 & 1,2 & 28,4 \\
\hline Ativismo de protesto & 85,1 & 14,9 & - & - & - & 14,9 \\
\hline \multicolumn{7}{|c|}{2008} \\
\hline Ativismo comunitário & 54,4 & 32,5 & 13,1 & - & - & 45,6 \\
\hline Ativismo partidário e eleitoral & 47,3 & 39,1 & 10,6 & 3,0 & & 52,7 \\
\hline Contato com atores políticos e governamentais & 68,3 & 15,6 & 9,6 & 4,8 & 1,7 & 31,7 \\
\hline Ativismo de protesto & 81,5 & 18,5 & - & - & - & 18,5 \\
\hline \multicolumn{7}{|c|}{2010} \\
\hline Ativismo comunitário & 69,9 & 22,8 & 7,3 & - & - & 30,1 \\
\hline Ativismo partidário e eleitoral & 53,9 & 34,5 & 9,9 & 1,7 & - & 46,1 \\
\hline Contato com atores políticos e governamentais & 77,5 & 12,5 & 7,7 & 1,7 & 0,6 & 22,5 \\
\hline Ativismo de protesto & 94,6 & 5,4 & - & - & - & 5,4 \\
\hline \multicolumn{7}{|c|}{2012} \\
\hline Ativismo comunitário & 68,5 & 24,6 & 6,9 & - & - & 31,5 \\
\hline Ativismo partidário e eleitoral & 54,6 & 35,0 & 8,0 & 2,4 & - & 45,4 \\
\hline Contato com atores políticos e governamentais & 81,5 & 8,0 & 6,8 & 2,7 & 1,0 & 18,5 \\
\hline Ativismo de protesto & 82,9 & 14,3 & 2,8 & - & - & 17,1 \\
\hline
\end{tabular}

Fonte: Dados do Barômetro das Américas, de autoria de Latin American Public Opinion Project (Lapop), disponível em: <www. LapopSurveys.org>. Elaboração própria.

8 Em duas variáveis, flutuações nos percentuais podem ser explicadas por mudanças na medida, com a alteração no período temporal contido nas categorias de resposta (CP5 e PROT1/PROT3). Por fim, cabe destacar que a inclusão da variável PROT6 em 2012 também contribui para a flutuação de percentuais referente à modalidade "ativismo de protesto". 


\section{Corrupção: concepções e medidas}

A corrupção ocupa considerável atenção de cientistas de diversas áreas. A explicação para tamanho interesse reside na sua ubiquidade em sociedades complexas, asseveram Lipset e Lenz (2002). A corrupção mostra-se presente ininterruptamente desde a antiguidade até a atualidade e sua manifestação não se restringe a determinados contextos institucionais e culturais. Talvez por conta de sua ubiquidade, Euben (1989) entende que a história conceitual da corrupção é incerta. Segundo o autor, o termo foi utilizado em dois contextos distintos: para fazer referência a uma atividade humana específica - como, por exemplo, o suborno -, ou em um sentido mais geral de destruição, devastação ou adulteração de um material orgânico. Desse modo, acreditamos que o vocábulo apresenta conotação negativa e é assimilado a noções de decadência, desintegração e degeneração.

Para Filgueiras (2008), é um equívoco escrever sobre uma teoria política da corrupção, já que não há, na tradição do pensamento político ocidental, consenso a respeito de seu significado. Por isso, de acordo com o autor, não se pode falar em uma teoria política sobre o fenômeno, mas de diferentes abordagens a respeito.

Sobre as abordagens, a visão de Heidenheimer, Johnston e Levine (1989) indica a existência de três tipos principais. Um grupo de cientistas, o mais numeroso, a compreende como estritamente relacionada à atuação de agentes públicos (Nye, 1967; Manzetti e Wilson, 2009). Outro grupo formula definições sobre a corrupção, ressaltando a natureza econômica do fenômeno (Rose-Ackerman, 1999). E uma terceira corrente teórica entende a corrupção como um fenômeno contrário à ideia de interesse público (Filgueiras, 2008; Seña, 1989; Calera, 1989; Valdés, 1995). Desse modo, a corrupção é apreendida sob três óticas distintas: 1) como ato infracional, que se opõe ou que transcende as leis e normas oficiais; 2) como um comportamento calculado, que beneficia o corruptor, dada as oportunidades específicas do contexto em que a ação se insere; e 3) como intimamente ligada ao sistema normativo vigente em cada sociedade, respectivamente. 
A partir dessas abordagens, é possível conceber diversos indicadores de corrupção a nível individual, mas utilizamos somente uma medida: a experiência do cidadão com situações de pedido de propina por algum agente. ${ }^{9}$ Especificamente, utilizamos somente as variáveis que questionam os entrevistados sobre pedido de suborno por policial ou por funcionário público. ${ }^{10}$ Temos motivos para seguir esse caminho. O primeiro é a qualidade da medida. Não se trata de percepções nem de valores, mas de convivência com atos corruptos. Desse modo, acreditamos que a medida que chamaremos de "experiência com corrupção" é a mais objetiva entre as existentes. Esta medida está livre de influência de aspectos subjetivos, como a cobertura midiática e as preferências políticas, que podem enviesar a resposta dos cidadãos a questões sobre corrupção. Em segundo lugar, é importante destacar que a medida de experiência com corrupção capta práticas de corrupção de pequena monta, que são possíveis de serem vivenciadas com frequência por qualquer cidadão. Por fim, o estudo de Bonifácio e Paulino (2015) destaca que a experiência com corrupção é a medida que melhor distingue engajamento ou não engajamento em atividades participativas entre os cidadãos das Américas e do Caribe, sobrepondo-se a medidas como percepção de corrupção entre funcionários públicos e tolerância à propina.

Há, porém, um problema técnico com essa medida no Barômetro das Américas. Existem mais variáveis sobre situações de pedido de propina ${ }^{11}$ que as utilizadas, mas não as utilizamos por apresentarem excesso de casos ausentes (missing values). Estas variáveis são sempre precedidas por uma pergunta-filtro. Por exemplo, pergunta-se primeiramente ao entrevistado se ele acessou o serviço público de saúde no último ano. Apenas se a resposta for positiva, é perguntado

9 Classificamos a medida como experiência com corrupção, em vez de vitimização por corrupção, como fazem Mitchell Seligson e parceiros em diversos trabalhos. Da maneira como estão redigidas, as questões só permitem ao entrevistado atestar o papel de vítima, mas é factível supor que parte dos respondentes exercem, na realidade, o papel de corruptor. A fim de evitar a posição do entrevistado como corruptor ou vítima, utilizamos o termo "experiência com corrupção".

10 Os códigos das variáveis no questionário do Barômetro das Américas são EXC2 e EXC6, respectivamente.

11 Para informações detalhadas sobre essas variáveis, procurar pelos códigos EXC11, EXC13, EXC14, EXC15 e EXC16 no questionário do Barômetro das Américas. 
se, para ser atendido em um hospital ou posto de saúde, o entrevistado teve que pagar propina. A maior parte dessas respostas é negativa; com isso, existe um grande percentual de valores ausentes em cada uma destas variáveis, o que torna a frequência de casos válidos diminuta, dificultando a análise dos dados.

Conhecidas as virtudes e as limitações da medida de experiência com corrupção, destacamos a frequência e a flutuação percentual de cada variável relacionada (tabela 3 ). Os percentuais de experiência com corrupção mostram-se modestos, para todos os quatro indicadores. É relativamente mais comum o pedido de suborno por parte dos policiais, variando entre $3,1 \%$ e $5,9 \%$ entre os quatro períodos temporais. Ademais, observamos certa constância nas frequências, havendo somente leves flutuações nos percentuais entre as rodadas. Talvez isso se explique pela natureza objetiva da medida: uma vez que se atém a eventos e não eventos, é de se esperar que ela seja pouco afetada por questões usualmente atreladas à corrupção, como notícias negativas sobre governos e representantes políticos, insatisfações com a qualidade das políticas públicas e avaliações a respeito da situação econômica e da vida.

Tabela 3 - Experiências com corrupção, de 2007 a 2012 (\%)

\begin{tabular}{c|c|c|c|c}
\hline & 2007 & 2008 & 2010 & 2012 \\
\hline Pedido de suborno por autoridade policial & 4,8 & 3,1 & 5,9 & 4,3 \\
\hline Pedido de suborno por funcionário público & 2,6 & 1,6 & 3,1 & 2,3 \\
\hline
\end{tabular}

Fonte: Dados do Barômetro das Américas.

Elaboração própria.

Tendo em vista que nosso interesse é avaliar o impacto das experiências com corrupção, de um modo geral, no comportamento participativo dos brasileiros, em vez de conduzirmos testes envolvendo as variáveis relativas a cada uma dessas experiências, consideramos mais interessante reduzi-las a uma medida integrada. Tal procedimento também favorece a análise dos dados em testes 
inferenciais, por aumentar a quantidade de casos na variável designada "experiência com corrupção".

\section{Corrupção e orientações políticas}

Tendo como foco as orientações políticas individuais, entendemos que estudos da área são quase consensuais ao indicarem os efeitos nocivos da corrupção para atitudes e comportamentos entendidos como cívicos. No campo normativo, os trabalhos de Hirschman (1983) e de Warren (2012) são referências para vislumbrarmos tais efeitos para o sistema político de uma forma geral.

Hirschman (1983) busca, em aspectos sociopsicológicos, a explicação para o envolvimento cíclico do indivíduo em atividades relacionadas às esferas pública (indivíduo identificado como "cidadão") e privada (indivíduo identificado como "consumidor"). A corrupção é importante para entender o desengajamento do "cidadão" em atividades da esfera pública, relacionadas ao ativismo político. A percepção e a vivência com atos de corrupção ao longo do tempo potencializam a conformação e a consequente imersão do cidadão em atos corruptos. Tal movimento é compreendido pelo autor como um sintoma de mudança de preferência, com o indivíduo passando a priorizar interesses particulares via ganhos materiais advindos da corrupção. A persistente imersão em atos corruptos leva os indivíduos a pensarem que as atividades públicas são atividades vis por natureza e, assim, o que inicialmente era uma reação de descontentamento com a esfera pública, torna-se um determinante de descontentamento adicional e profundo que, por sua vez, prepara o terreno para mais corrupção. Ao final do processo, o espírito público é completamente eliminado. Nessas condições, a corrupção pode proporcionar ao "cidadão" uma rápida transição de volta ao seu papel de "consumidor".

Na perspectiva de Warren (2012), a corrupção mina os processos de natureza inclusiva da política, como a relação entre representantes e representados, pois compromete o poder de voto e de fala dos indivíduos que almejam influenciar as decisões coletivas, removendo o poder e os recursos da arena pública para as relações 
parciais, particulares e privadas. Como consequência, tem-se o enfraquecimento da legitimidade democrática devido à exclusão de grande parte da população das decisões que a afeta. Ademais, a corrupção afeta a cultura democrática, destaca o autor. Se a corrupção alastra-se, perde-se paulatinamente a confiança no processo de tomada de decisões públicas - enxergando-o como não publicamente disponível e justificável - e, como consequência, é provável que os indivíduos tornem-se cada vez mais cínicos a respeito do discurso público e da deliberação. A partir dessas considerações, Warren sugere que a corrupção possibilita a diminuição do horizonte das ações coletivas, encolhendo o domínio da democracia nesse campo.

Hirschman (1983) e Warren (2012) destacam que o envolvimento do indivíduo com as práticas corruptas tem consequências negativas tanto para o caráter democrático do sistema político quanto para as atitudes e os comportamentos cívicos. Contudo, suas obras têm a limitação de serem essencialmente teóricas, normativas, atemporais e sem delimitação de contexto.

Já os estudos a seguir, para além de desenvolverem discussões teóricas, oferecem análises empíricas sobre o papel da experiência com corrupção nas atitudes políticas no contexto latino-americano.

Em Zéphyr (2008) e Seligson $(2001 ; 2002)$ há considerações uníssonas, no sentido de atestar a associação de experiência com a corrupção a baixos patamares de adesão ao regime político democrático. Utilizando dados do Barômetro das Américas de 2006, Zéphyr identifica que quanto maiores são os níveis de experiência com corrupção dos indivíduos, menores são suas taxas de adesão à democracia. No primeiro trabalho de Seligson, são utilizados dados de pesquisas de opinião da população nicaraguense de 1996 e 1998, a primeira conduzida anteriormente e a segunda após a realização de uma campanha nacional de conscientização contra a corrupção. Já no segundo trabalho, os dados são de pesquisas de opinião entre cidadãos bolivianos e paraguaios em 1998 e entre salvadorenhos e nicaraguenses em 1999. Em ambos os estudos, o autor encontra uma relação negativa entre experiência com corrupção e legitimidade 
democrática. No trabalho de 2002, Seligson também investiga os efeitos da experiência com corrupção na confiança interpessoal, fenômeno entendido como facilitador da formação de profundas e duráveis associações civis entre os indivíduos. Os efeitos negativos da corrupção mostram-se, mais uma vez, presentes: quanto mais experiência com corrupção, menos confiança interpessoal.

Salinas e Booth (2011) conduzem a investigação no sentido de verificar o papel da experiência com corrupção em indicadores de civismo, tais como a adesão ao regime político democrático, o apoio ao direito de participação política e a tolerância em relação a formas contestatórias de expressão política. Os dados utilizados são do Barômetro das Américas, de 2010. Em todos os casos, os autores observaram associações negativas, concluindo que a corrupção é nociva ao civismo.

Para Bohn (2012), a legitimidade dos regimes democráticos deriva do apoio em massa aos seus principais processos, tais como eleições livres e justas, liberdades e direitos institucionalizados e transparência e accountability nas instituições públicas. A manifestação da corrupção no ambiente democrático teria o potencial de viciar as interações entre indivíduo e estrutura, causando a diminuição de confiança e de satisfação dos indivíduos com princípios e instituições democráticas. A partir dessas considerações, a autora direciona a sua investigação, analisando o papel da experiência com corrupção na satisfação dos cidadãos com a democracia realmente existente, com base em dados do Barômetro das Américas de 2010. Bohn identifica que quanto maiores são os níveis de experiência com corrupção, menor é a satisfação com a democracia.

Todos os autores abordados anteriormente esclarecem que a proximidade do indivíduo com a corrupção torna-o menos suscetível a expressar atitudes políticas congruentes com os princípios democráticos. Ou seja, a corrupção teria efeitos nocivos a uma cultura cívica.

Entre os especialistas em comportamento político brasileiros e brasilianistas, a investigação usual é sobre os efeitos da corrupção no sucesso eleitoral de políticos envolvidos em escândalos de 
corrupção e nas escolhas eleitorais dos cidadãos. ${ }^{12}$ Os trabalhos de Hunter e Power (2007), Rennó (2008) e Rennó e Hoepers (2010) atêm-se ao contexto de 2006, marcado pela eleição presidencial que reelegeu Lula e pelo amplo noticiário a respeito do escândalo do "mensalão".

No primeiro trabalho, os autores identificam que os grupos de eleitores com menores e maiores recursos socioeconômicos diferenciam-se a respeito do nível de informação sobre corrupção e dos efeitos que os escândalos de corrupção possuem na decisão do voto. $\mathrm{O}$ primeiro grupo de eleitores é o menos informado sobre os escândalos de corrupção e o que menos leva esta informação e estes efeitos em consideração para a conformação da confiança no então presidente Lula e para a avaliação de seu governo. Sabendo ou não dos escândalos, este grupo de eleitores também tende a recompensar eleitoralmente Lula pelo desempenho positivo de seu governo nas políticas sociais e na condução da economia. Por outro lado, os mais escolarizados e informados mostram-se mais intolerantes com os cidadãos vistos como corruptores: enquanto $40 \%$ dos analfabetos e $31 \%$ dos cidadãos que possuem até o Ensino Primário completo concordam com a frase "se alguém é eleito para um cargo público, deve usar o cargo como se fosse sua propriedade particular, em seu benefício", essa concordância atinge apenas 5\% dos cidadãos com Ensino Médio e 3\% com Ensino Superior.

Hunter e Power (2007) afirmam que os resultados corroboram duas teses da literatura especializada. Uma que indica que os eleitores com maior acesso à informação são mais propensos a atuar de maneira punitiva em relação aos políticos, e outra que considera que os cidadãos com menor segurança econômica, no momento de se expressarem politicamente, priorizam suas necessidades básicas sobre outras questões, tais como ética e transparência, enquanto

12 Moisés (2010) constitui-se uma exceção, ao analisar os efeitos da corrupção para a qualidade da democracia. Contudo, o autor traz poucos esclarecimentos a duas questões importantes: 1) não especifica o que entende por "rouba, mas faz", tampouco relata os seus indicadores; e 2) em testes de regressão realizados, os resultados são relatados pelo autor, mas não mostrados ao longo do texto. 
cidadãos privilegiados tendem a enfatizar os valores pós-materialistas em maior medida.

Rennó e Hoepers (2010) investigam o voto estratégico punitivo na eleição presidencial de 2006. Especificamente, trata-se de identificar eleitores comumente simpáticos à candidatura de Lula que não votaram nele no primeiro turno como forma de puni-lo pelo envolvimento de membros de seu partido político em escândalos de corrupção, mas que o apoiaram no segundo turno. Devido à alta sofisticação do voto estratégico punitivo, os autores verificam que apenas $4 \%$ dos eleitores tiveram tal tipo de comportamento. Contudo, essa pequena margem de eleitores mostrou-se decisiva para a ocorrência do segundo turno e para assegurar a vitória de Lula no turno final da eleição.

Com base nesses resultados, Rennó e Hoepers (2010) consideram corroborada a hipótese central de que uma pequena, mas relevante, parcela do eleitorado brasileiro usou um tipo de voto estratégico diferenciado para a definição de suas escolhas eleitorais no pleito de 2006. Os eleitores de Heloísa Helena encaixam-se perfeitamente nesse perfil: eram antigos apoiadores de Lula, frustrados com o envolvimento de seu governo em escândalos de corrupção e que decidiram puni-lo no primeiro turno. Contudo, no segundo turno, com a possibilidade de praticarem o voto útil, levaram em consideração outros atributos do desempenho do governo para voltar a apoiar Lula.

Já o foco de Rennó (2008) é a eleição para deputado federal em 2006. O autor pesquisa as consequências do envolvimento de deputados federais em escândalos de corrupção para as suas chances de reeleição, supondo que este envolvimento possa manchar a reputação do deputado e ferir a lealdade que possui com os seus eleitores. O autor segmenta os deputados da 52a legislatura (2003-2006) entre envolvidos ou não com escândalos de corrupção e identifica que o primeiro grupo tem maiores taxas de tentativa de reeleição e de sucesso eleitoral, em comparação ao segundo grupo. Os testes de regressão realizados confirmam essas relações, mesmo levando 
em conta outros fatores explicativos, como quantidade de recurso concentrado (pork barrel) e gastos de campanha.

Para Rennó (2008), esses resultados são indícios de que os eleitores não são completamente alheios ao que os políticos fazem e punem aqueles que se envolvem em corrupção. Ainda assim, a alta despesa com campanha constitui-se um escudo importante para os políticos envolvidos em escândalos, no sentido em que é o único fator que aumenta as chances de sucesso eleitoral entre deputados com pecha de corruptos.

Em Rennó e Ames (2014), o contexto enfocado são as eleições de 2010. Eles investigam o quanto as discussões sobre o aborto e sobre os escândalos de corrupção, envolvendo uma ministra de governo próxima à candidata do Partido dos Trabalhadores (PT) à Presidência em 2010, a poucas semanas do primeiro turno, alteraram as intenções de voto. Os autores utilizam dados de pesquisa de painel com três pontos no tempo (abril, setembro e novembro) e observam que as discussões sobre o aborto pouco alteraram as preferências eleitorais entre os três principais candidatos à Presidência - Marina Silva, José Serra e Dilma Rousseff -, mas que os escândalos de corrupção tiveram um forte impacto.

Rennó e Ames identificam as maiores alterações de intenção de voto na fase final de campanha, quando as duas questões destacadas anteriormente vieram à tona no embate eleitoral. Ademais, para eles não restam dúvidas de que a candidatura de Dilma foi negativamente afetada por escândalos de corrupção: parte dos eleitores que consideravam a corrupção um problema nacional e que intencionavam votar em Dilma em setembro mudaram de opinião em novembro, na rodada de pesquisa que capta o voto declarado no primeiro turno. Os resultados destacados pelos autores indicam que a migração de maior parte deste voto foi de Dilma para Serra. Assim, afirmam que a questão da corrupção sobrepôs-se à do aborto como fator-chave para entender a incapacidade do PT de vencer as eleições no primeiro turno. Serra, que foi para o segundo turno das eleições, foi o mais beneficiado por esse processo. 
Os autores destacam que os dados longitudinais permitem explorar melhor as nuances da disputa eleitoral e afirmam que o "purgatório eleitoral" de Dilma (duas semanas anteriores à realização do segundo turno) está muito mais relacionado à emergência de escândalos de corrupção do que à discussão sobre o aborto, fazendo com que sua candidatura fosse prejudicada, ao passo que a candidatura de Serra foi favorecida.

Em consonância com os trabalhos que se atém ao contexto latino-americano, as investigações de Hunter e Power (2007) e de Rennó e parceiros $(2008 ; 2010 ; 2014)$ sobre o caso brasileiro apontam que corrupção tem efeitos sobre as escolhas eleitorais dos brasileiros, embora estes efeitos sejam marginais e diferenciados entre os diferentes segmentos da população.

Contudo, os escassos estudos sobre a relação entre corrupção e participação política concedem resultados dissonantes aos destacados anteriormente. Os trabalhos de Olsson (2014) e de Bonifácio e Paulino (2015) são exemplares.

Em Olsson (2014), investiga-se a relação entre percepção de corrupção no serviço público e três tipos de participação política (comparecimento eleitoral e participação política institucionalizada e não institucionalizada) em 33 países - de regiões da Europa, da Ásia e da América Latina - na rodada de dados pertinente aos anos de 2003 a 2006 do International Social Survey Programme (ISSP). A autora observa que a associação negativa entre percepção de corrupção e participação política institucionalizada e não institucionalizada só se mostra presente em modelos univariados. À medida que se adicionam variáveis nos modelos de regressão, esse efeito esfuma-se, identificando-se uma associação positiva de baixo patamar de intensidade e desprovida de significância estatística. $\mathrm{Ou}$ seja, não se observa qualquer padrão de associação entre percepção de corrupção e atividades participativas não eleitorais. Já para comparecimento eleitoral, observa-se uma clara tendência de associação negativa: quem percebe corrupção no serviço público tem menores níveis de presença em votações. 
Já o artigo de Bonifácio e Paulino (2015) atém-se à relação entre corrupção e participação política entre americanos e caribenhos. Utilizando dados do Barômetro das Américas, rodadas de 2006, 2008, 2010 e 2012, os autores identificam que indivíduos com experiência com situações de pedidos de propina por policiais e funcionários públicos apresentam mais chances de engajamento em atividades participativas que os indivíduos que não possuem tal experiência. Esse resultado é válido para quatro das cinco modalidades de participação política analisadas: ativismo comunitário, ativismo partidário e eleitoral; contato com atores políticos e governamentais; e ativismo de protesto. Comparecimento eleitoral constitui-se uma exceção, sem padrão identificável.

Os dois trabalhos contribuem para um problema de pesquisa pouco investigado e os resultados que alcançam vão em desencontro com a maior parte da literatura de comportamento político - parte dela anteriormente abordada -, que afirma a existência de associação negativa entre experiência com corrupção e atitudes políticas cívicas. Temos, portanto, contribuições com visões contraditórias acerca dos possíveis efeitos da proximidade com a corrupção sobre as orientações políticas individuais. Isso dificulta a construção de hipóteses, dado que essa tarefa é menos complexa quando se tem consenso da literatura especializada a respeito de uma relação.

Apesar dos dilemas envolvidos, decidimos construir uma hipótese afinada com os dois últimos trabalhos abordados, por conta da proximidade de seu desenho de pesquisa com o nosso. Desse modo, hipotetizamos, para todas as modalidades de participação política, que: (H1) os indivíduos que possuem experiência com corrupção apresentam maiores chances de engajamento em atividades participativas que os indivíduos que não possuem tal tipo de experiência.

Embora seja importante considerar a existência de diversas e contraditórias motivações para a adesão a cada uma das modalidades 
de participação política, ${ }^{13}$ não discriminamos diferentes hipóteses para cada uma delas porque não vislumbramos diferenças no processo de engajamento político, dado que ele é sempre voluntarista e ativista. Ademais, os trabalhos que abordamos nesse tópico são claros, ao indicarem tanto um efeito nocivo quanto uma associação positiva da corrupção, com atitudes e participação políticas, respectivamente. Nesses dois conjuntos de trabalhos, quase todos indicam não haver qualquer evidência que diferencie a relação da corrupção com os diversos fenômenos investigados. Essas considerações servem-nos de referência para construirmos uma única hipótese acerca da relação entre corrupção e participação política.

\section{Permissividade à corrupção}

Embora seja necessário diagnosticar um possível padrão de associação entre corrupção e participação política nos contextos selecionados, isso não é suficiente. Também é essencial extrair algum significado dessa relação e identificar o grau de permissividade à corrupção do brasileiro que alia experiência com corrupção e participação política. Especificamente, buscamos entender se a proximidade com atos corruptos e o simultâneo ativismo político levam esse indivíduo, por um lado, à busca de uma transformação da situação vigente, tendo como horizonte um cenário de probidade ou, por outro lado, se ele tende a relativizar a gravidade da corrupção, conformando-se com os atos corruptos. Ou seja, buscamos identificar se há uma predominância de indignação ou de resignação desse perfil social.

A ideia de permissividade à corrupção remete a diversas atitudes favoráveis ou, pelo menos, não contrárias à manifestação de atos corruptos na sociedade. Como exemplo, podemos citar as considerações sobre o "rouba, mas faz" e sobre a compra de votos, o posicionamento em situações hipotéticas de pequenas corrupções, a tolerância ao pagamento de propina, entre outros. Todas essas

13 Cabe ressaltar que nossa definição de participação política e a posterior análise de dados das atividades participativas têm como referência a finalidade do fenômeno, e não as motivações individuais que justificam a sua ocorrência. 
questões são abarcadas pelo Barômetro das Américas, mas apenas a última - tolerância ao pagamento de propina - é aplicada em todas as rodadas, permitindo comparações longitudinais.

Dois possíveis cenários mostram-se os mais interessantes na análise da permissividade à corrupção do indivíduo que alia experiência com corrupção e participação política: a situação dele se mostrar o mais ou o menos tolerante ao pagamento de propina, em relação aos demais perfis. A análise é comparativa, tendo como referências os outros perfis sociais, que apresentam a interação das demais categorias de evento e não evento em relação à experiência com corrupção e participação política.

Para a formulação de hipótese, baseamo-nos em resultados de estudos sobre os efeitos da corrupção em atitudes políticas. Desse modo, hipotetizamos, para todas as modalidades de participação política, que: (H2) o indivíduo que alia experiência com corrupção e ativismo político tem mais probabilidade de ser tolerante ao pagamento de propina (mais permissivo à corrupção) que os demais indivíduos.

\section{Corrupção e participação política no Brasil: análise dos dados}

Construímos modelos de regressão logística bivariada tendo como variável a ser explicada cada uma das quatro modalidades de participação política, utilizando os dados de todas as rodadas. Realizamos modelos progressivos, que continham inicialmente apenas a variável binária experiência com corrupção, ${ }^{14}$ adicionando, em um segundo momento, as variáveis de controle, referentes às condições socioeconômicas dos entrevistados: sexo, idade, escolaridade e renda ${ }^{15}$ (tabela 4 ).

Na coluna referente a cada modalidade de participação política há os números 1 e 2, que indicam o modelo inicial e o completo,

14 É a única variável explicativa dos modelos construídos e tem natureza binária, sendo o valor 0, de não evento, usado como referência.

15 A variável sobre sexo é nominal, ficando o feminino a referência. As demais variáveis sobre condições socioeconômicas são contínuas. 
respectivamente. Buscando uma leitura mais clara dos dados, optamos por usar o efeito percentual em vez da razão de chance. ${ }^{16}$

Os resultados mostram uma clara uniformidade no que se refere aos efeitos da experiência com corrupção no ativismo político. Nos modelos inicial e completo de todas as rodadas de dados e modalidades de participação política, observa-se que os indivíduos com experiência com corrupção têm mais chances de se engajarem em atividades participativas, tendo como referência aqueles que não possuem tal tipo de experiência. Na quase totalidade dos casos, há significância estatística e o efeito percentual é de moderado a elevado patamar, apresentando valores acima de 40\%. Ao longo da série temporal, os maiores valores sempre se concentram no ativismo de protesto. Por fim, cabe destacar que o mesmo padrão de associação positiva observado nos modelos de regressão inicial e completo indica a existência de uma relação robusta entre corrupção e participação política, afastando qualquer possibilidade de relação espúria. Todos esses resultados são fortes evidências para a corroboração da primeira hipótese. Em período recente, há uma clara relação de sentido positivo entre corrupção e participação política no Brasil.

Vamos além da identificação do padrão associativo na relação entre as medidas de corrupção e participação política e investigamos as suas consequências, analisando o quanto que o perfil que alia experiência com corrupção e ativismo político é permissivo à corrupção, atitude medida via tolerância ao pagamento de propina. Para tanto, foram realizados testes de valores preditos, que geram probabilidades de permissividade à corrupção para cada perfil social construído. ${ }^{17}$

16 Os valores de efeito percentual são gerados a partir da aplicação da seguinte equação: Exp (B) - 1 * 100 .

17 Os perfis são construídos a partir da interação de categorias indicadoras de evento e não evento de experiência com corrupção e participação política. Assim, são quatro os perfis: experiência com corrupção e participação política; experiência com corrupção e não participação política; não experiência com corrupção e participação política; e não experiência com corrupção e não participação política. 
Tabela 4 - Preditores de participação política, por modalidade e rodada (\%)

\begin{tabular}{|c|c|c|c|c|c|c|c|c|}
\hline & \multicolumn{2}{|c|}{ CAPG } & \multicolumn{2}{|c|}{$A C$} & \multicolumn{2}{|c|}{ APE } & \multicolumn{2}{|c|}{ AP } \\
\hline & 1 & 2 & 1 & 2 & 1 & 2 & 1 & 2 \\
\hline \multicolumn{9}{|c|}{2007} \\
\hline Experiência com corrupção & $93,1^{* * *}$ & $121,3^{* * *}$ & $75,0^{* * *}$ & $74,5^{* * *}$ & $141,1^{* * *}$ & $121,1^{* * *}$ & $326,8^{* * *}$ & $249,8^{* * *}$ \\
\hline Sexo masculino & - & $-21,6^{*}$ & - & 3,7 & - & $34,6^{* * *}$ & - & $40,9^{* *}$ \\
\hline Idade & - & 0,3 & - & $1,4^{* * *}$ & - & 0,3 & - & 0,1 \\
\hline Renda familiar & - & $-2,2$ & - & 4,6 & - & $-4,0$ & - & 2,3 \\
\hline Escolaridade & - & $-5,2$ & - & 0,8 & - & $3,8^{* * *}$ & - & $13,0^{* * *}$ \\
\hline Constante & $-67,0^{* * *}$ & $-50,0^{* * *}$ & $-50,0^{* * *}$ & $-80,0^{* * *}$ & $-25,0 * * *$ & $-54,4^{* * *}$ & $-86,0^{* * *}$ & $-97,4^{* * *}$ \\
\hline Qui-quadrado & $7,9^{* * *}$ & $19,5^{* * *}$ & $6,2^{* * *}$ & $22,7^{* * *}$ & $15,0^{* * * *}$ & $27,5^{* * *}$ & $33,2^{* * *}$ & $78,0^{* * *}$ \\
\hline Pseudo $R^{2}$ & 0,006 & 0,015 & 0,004 & 0,015 & 0,009 & 0,017 & 0,035 & 0,082 \\
\hline Log likehood & $-638,5$ & $-632,7$ & $-747,7$ & $-739,5$ & $-770,9$ & $-764,7$ & $-455,0$ & $-432,6$ \\
\hline \multicolumn{9}{|c|}{2008} \\
\hline Experiência com corrupção & 22,7 & 25,9 & 47,2 & 52,3 & $78,2^{* * *}$ & $70,6^{* *}$ & - & - \\
\hline Sexo masculino & - & $-5,4$ & - & $-0,2$ & - & 14,5 & - & - \\
\hline Idade & - & 0,6 & - & $1,4^{* * *}$ & - & $-0,8^{* *}$ & - & - \\
\hline Renda familiar & - & $-1,6$ & - & $-8,6^{*}$ & - & 2,9 & - & - \\
\hline Escolaridade & - & 0,5 & - & 0,7 & - & $4,5^{* *}$ & - & - \\
\hline Constante & $-54,2^{* * *}$ & $-64,0^{* * * *}$ & $-50,0^{* * * *}$ & $-65,5^{* * *}$ & 7,7 & $-4,5$ & - & - \\
\hline Qui-quadrado & 0,6 & 3,19 & 2,05 & $15,74^{* * *}$ & $5,44^{* * *}$ & $30,2^{* * *}$ & - & - \\
\hline Pseudo $R^{2}$ & 0,0004 & 0,0021 & 0,0015 & 0,0125 & 0,0031 & 0,0184 & - & - \\
\hline Log likehood & $-809,6$ & $-745,3$ & $-676,9$ & $-622,4$ & $-885,4$ & $-803,8$ & - & - \\
\hline
\end{tabular}




\begin{tabular}{c|c|c|c|c|c|c|c|c}
\hline \multirow{2}{*}{} & \multicolumn{2}{|c|}{ CAPG } & \multicolumn{2}{c|}{ AC } & \multicolumn{2}{c}{ APE } & \multicolumn{2}{c}{ AP } \\
\cline { 2 - 9 } & 1 & 2 & 1 & 2 & 1 & 2 & 1 & 2 \\
\hline \multicolumn{7}{|c|}{2010} \\
\hline Experiência com corrupção & $49,2^{* *}$ & $45,5^{* *}$ & $41,3^{*}$ & $39,9^{*}$ & $84,9^{* * *}$ & $70,9^{* * *}$ & $113,4^{* * *}$ & $91,0^{* *}$ \\
\hline Sexo masculino & - & 5,5 & - & 14,7 & - & $22,3^{* *}$ & - & 20,2 \\
\hline Idade & - & $-0,1$ & - & 0,8 & - & $-0,1$ & - & $-1,7^{* * *}$ \\
\hline Renda familiar & - & $-0,1$ & - & $-0,1$ & - & $-0,1$ & - & 0,3 \\
\hline Escolaridade & - & 0,3 & - & $-0,1$ & - & 0,5 & - & 0,4 \\
\hline Constante & $-71,0^{* * *}$ & $-71,0^{* * *}$ & $-73,8^{* * *}$ & $-75,0^{* * *}$ & $-7,7^{* *}$ & 0,1 & $-99,5^{* * *}$ & $-90,0^{* * *}$ \\
\hline Qui-quadrado & $4,8^{* *}$ & 8,4 & $2,7^{*}$ & 8,4 & $13,3^{* * *}$ & $32,6^{* * *}$ & $7,2^{* * *}$ & $18,0^{* * *}$ \\
\hline Pseudo $R^{2}$ & 0,0019 & 0,0033 & 0,0013 & 0,0039 & 0,0044 & 0,0107 & 0,0067 & 0,0165 \\
\hline Log likehood & $-1277,4$ & $-1275,6$ & $-1073,1$ & $-1070,3$ & $-1521,3$ & $-1511,7$ & $-544,0$ & $-538,6$ \\
\hline
\end{tabular}

2012

\begin{tabular}{c|c|c|c|c|c|c|c|c}
\hline Experiência com corrupção & $87,9^{* *}$ & $105,3^{* * *}$ & $89,0^{* *}$ & $93,0^{* *}$ & $116,2^{* * *}$ & $92,4^{* * *}$ & $111,7^{* *}$ & $97,8^{* *}$ \\
\hline Sexo masculino & - & $-4,5$ & - & 21,1 & - & $49,1^{* * *}$ & - & 4,1 \\
\hline Idade & - & $1,7^{* * *}$ & - & $1,7^{* * *}$ & - & $0,8^{* *}$ & - & $-0,5$ \\
\hline Renda familiar & - & $-4,7^{* *}$ & - & $-0,1$ & - & $-2,7$ & - & $-0,5$ \\
\hline Escolaridade & - & 1,0 & - & 1,9 & - & 2,8 & - & $5,8^{* *}$ \\
\hline Constante & $-78,2^{* * *}$ & $-81,8^{* * *}$ & $-55,8^{* * *}$ & $-81,4^{* * *}$ & $-21,3^{* * *}$ & $-50,0^{* *}$ & $-80,3^{* * *}$ & $-86,0^{* *}$ \\
\hline Qui-quadrado & $5,4^{* *}$ & $23,8^{* * *}$ & $7,2^{* * *}$ & $25,8^{* * *}$ & $10,8^{* * *}$ & $27,5^{* * *}$ & $7,6^{* * *}$ & $18,8^{* * *}$ \\
\hline Pseudo $R^{2}$ & 0,0038 & 0,0174 & 0,0039 & 0,0147 & 0,0053 & 0,0143 & 0,0056 & 0,0145 \\
\hline Log likehood & $-711,2$ & $-671,3$ & $-920,2$ & $-867,3$ & $-1008,6$ & $-948,3$ & $-677,2$ & $-641,7$ \\
\hline
\end{tabular}

Fonte: Dados do Barômetro das Américas, de autoria de Latin American Public Opinion Project (Lapop), disponível em: <www. LapopSurveys.org>.

Elaboração própria.

Notas: ${ }^{*}=p$ valor menor/igual a 0,10 .

$*^{*}=p$ valor menor ou igual a 0,05 .

$*^{* * *}=p$ valor menor ou igual a 0,01 .

Obs.: $\mathrm{CAPG}=$ contato com atores políticos e governamentais; $\mathrm{AC}=$ ativismo comunitário; $\mathrm{APE}=$ ativismo partidário e eleitoral; $\mathrm{AP}$ $=$ ativismo de protesto. 
Ao contrário dos resultados sobre a relação entre corrupção e participação política, os resultados não são uniformes para a permissividade à corrupção. A partir dos dados contidos no gráfico 1 e na tabela 5, identificamos dois perfis mais permissivos: os perfis que aliam experiência com corrupção e não participação ("Exp*NPart”, área sombreada na tabela) e experiência com corrupção e participação ("Exp* Part”) praticamente dividem os casos de maior permissividade. Analisando por modalidade de participação política, observamos que o primeiro perfil citado tende a ser o mais permissivo à corrupção em contato com atores políticos e governamentais e em ativismo comunitário, sendo que o segundo perfil ocupa essa posição em relação ao ativismo partidário e eleitoral e ao ativismo de protesto.

Quando o foco da análise é a menor permissividade à corrupção (gráfico 1 e tabela 6), o perfil que combina não experiência com corrupção e não participação política ("NExp*NPart", áreas sombreadas na tabela) predomina, ocupando esse papel em dez dos 15 casos possíveis.

A maior limitação desses dados - melhor visualizados no Apêndice A - é a ausência de diferenciação probabilística quando se leva em conta a margem de erro. Porém, a identificação dos padrões de forma consistente ao longo dos anos é um contraponto e nos serve de referência para atestarmos a sua validade.

Em suma, o conjunto desses resultados não corroboram a segunda hipótese. Não podemos afirmar que o indivíduo que possui como características a combinação de proximidade com corrupção e de ativismo político é o mais permissivo à corrupção, usando a tolerância ao pagamento de propina como indicador.

Contudo, um padrão é claramente detectado: aqueles que possuem experiência com corrupção, independentemente de serem ou não politicamente participativos, são os mais permissivos à corrupção. Isto é, o posicionamento resignado e conformista encontra terreno fértil entre aqueles tocados pela corrupção, o que se constitui mais uma evidência nociva do fenômeno para o civismo. 
Tabela 5 - Síntese dos resultados para maior permissividade à corrup̧̧ão

\begin{tabular}{c|c|c|c|c}
\hline \multirow{2}{*}{} & \multicolumn{4}{|c}{ Tolerância ao pagamento de propina } \\
\cline { 2 - 5 } & 2006 & 2008 & 2010 & 2012 \\
\hline CAPG & Exp*NPart & Exp*NPart & Exp*NPart & Exp*Part \\
\hline AC & Exp*NPart & Exp*NPart & Exp*NPart & Exp*NPart \\
\hline APE & Exp*Part & Exp*NPart & Exp*Part & Exp*Part \\
\hline AP & Exp*Part & NSA & Exp*Part & Exp*Part \\
\hline
\end{tabular}

Fonte: Dados do Barômetro das Américas, de autoria de Latin American Public Opinion Project (Lapop), disponível em: <www. LapopSurveys.org >.

Elaboração própria.

Obs.: Exp*NPart = experiência com corrupção e não participação política e Exp*Part = experiência com corrupção e participação política.

Tabela 6 - Síntese dos resultados para menor permissividade à corrupção

\begin{tabular}{c|c|c|c|c}
\hline \multirow{2}{*}{} & \multicolumn{4}{|c}{ Tolerância ao pagamento de propina } \\
\cline { 2 - 5 } & 2006 & 2008 & 2010 & 2012 \\
\hline CAPG & NExp*NPart & NExp*Part & NExp*Part & NExp*NPart \\
\hline AC & NExp*NPart & NExp*NPart & NExp*Part & NExp*Part \\
\hline APE & NExp*NPart & NExp*NPart & NExp*NPart & NExp*NPart \\
\hline AP & NExp*NPart & NSA & NExp*Part & NExp*NPart \\
\hline
\end{tabular}

Fonte: Dados do Barômetro das Américas, de autoria de Latin American Public Opinion Project (Lapop), disponível em: <www. LapopSurveys.org>.

Elaboração própria.

Obs.: NExp*NPart = não experiência com corrupção e não participação política e NExp*Part = não experiência com corrupção e participação política. 
Gráfico 1 - Permissividade à corrupção dos perfis sociais, em 2012 (em probabilidade)
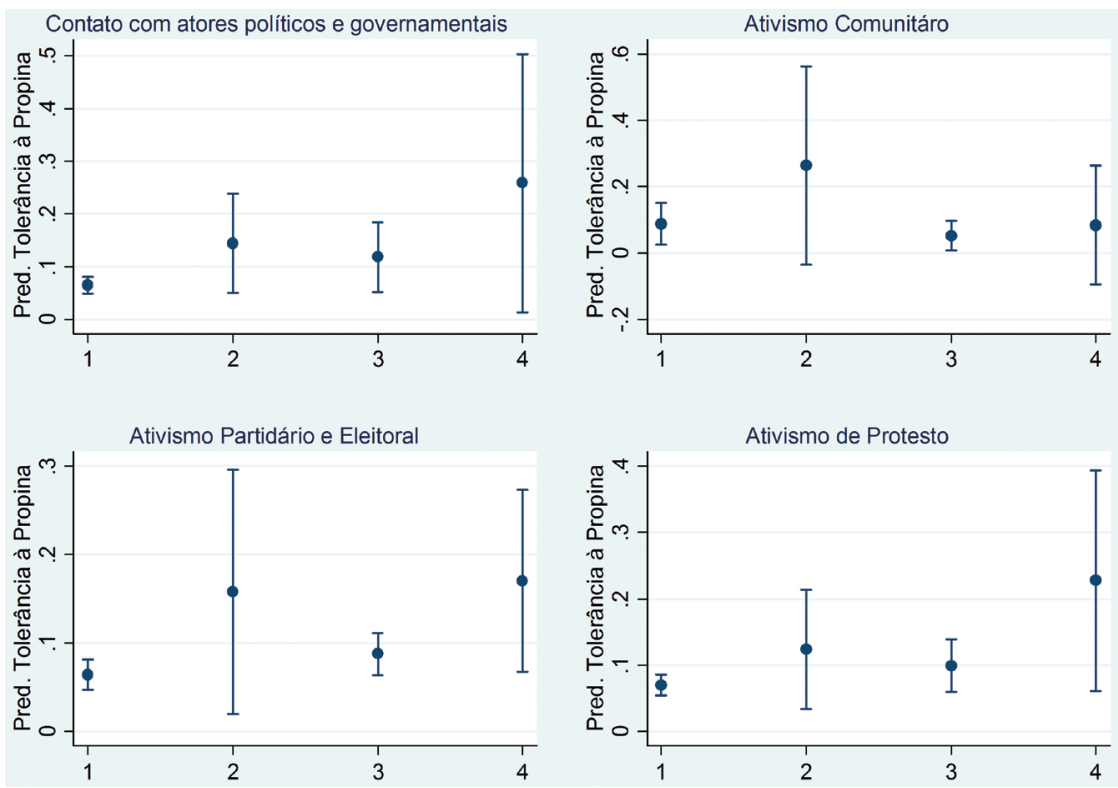

Fonte: Dados do Barômetro das Américas, de autoria de Latin American Public Opinion Project (Lapop), disponível em: <www. LapopSurveys.org>.

Elaboração própria.

Obs.: 1 = não experiência e participação; 2 = experiência e não participação; 3 = não experiência e participação; e 4 = experiência e participação.

\section{Considerações finais}

Investigamos um problema de pesquisa ainda inédito para o contexto nacional e os resultados alcançados contribuem, de um lado, para confirmar determinadas tendências já identificadas por especialistas em outros contextos e períodos históricos e, de outro lado, para lançar luzes a novos achados inerentes à relação entre corrupção e participação política.

A multidimensionalidade da participação política foi confirmada para o caso brasileiro. É mais uma evidência, entre as várias já disponibilizadas por diversos outros autores, de que é descabida qualquer consideração que direcione as atividades participativas para um único alvo - os governos de diversas esferas - e/ou que as 
aprisionem a uma arena específica - como a eleitoral. O estudo de Milbrath (1965), neste sentido, torna-se cada vez mais obsoleto.

A natureza da relação entre corrupção e participação política assume os mesmos contornos do que foi identificado por Bonifácio e Paulino (2015), que se remetem ao contexto americano e caribenho. Nesse caso, não se pode considerar o resultado como "mais do mesmo", dada a escassa produção científica com esse desenho de pesquisa. Trata-se mais da confirmação de uma tendência ainda pouco conhecida pelos politólogos devido ao caráter incomum do desenho de pesquisa adotado.

Destacamos a solidez do padrão associativo positivo entre experiência com corrupção e ativismo político. Tal como no estudo anteriormente citado, diagnosticamos associações de direção invariável e propensões de moderada a alta magnitude entre as modalidades de participação e ao longo do período temporal analisado. Esse diagnóstico nos deixa convictos de que a relação entre corrupção e participação política no Brasil é robusta e está longe de se constituir uma mera espuriedade.

A identificação da associação positiva entre corrupção e participação política é de suma importância, mas o sucesso em conquistar esse resultado leva a uma indagação quase que imediata: qual a importância disso para refletirmos a respeito da qualidade da democracia e do civismo? A tentativa de responder com alguma propriedade a essa indagação dá-se via testes de valores preditos, que concedem a probabilidade de diferentes perfis sociais de serem tolerantes ao pagamento de propina, um indicador possível de permissividade à corrupção.

O que se mostra bastante evidente é que vivenciar situações de pedido de propina por agentes públicos fomenta a resignação e o conformismo com atos corruptos. Os perfis que aliam experiência com corrupção e participação ou não participação política dividem os casos de maiores probabilidades de permissividade à corrupção. Em nenhum dos casos algum destes dois perfis mostram-se os menos permissivos à corrupção ou se aproximam dessa situação. 
A partir dessa verificação, o ensaio teórico de Hirschman (1983) parece-nos válido, embora não possamos operacionalizá-lo em sua plenitude. Sem dúvida, faltam peças a serem encaixadas no ciclo de participação proposto por esse autor (grande acontecimento político $\rightarrow$ imersão em atividades políticas $\rightarrow$ percepção de corrupção no setor público $\rightarrow$ decepção $\rightarrow$ retorno às atividades da vida privada), mas os resultados encontrados são evidências de que a convivência entre ativismo político e corrupção é possível e de que a proximidade com os atos corruptos, no mínimo, potencializa a resignação, formando uma massa de indivíduos conformados com a sua manifestação na sociedade.

$\mathrm{O}$ aprofundamento das análises nessa questão impõe-se como necessidade para futuros estudos. Acreditamos que o tratamento dos dados que desenvolvemos tem grandes virtudes, por trabalhar com uma considerável gama de variáveis em quatro pontos no tempo, desenvolvendo um desenho de pesquisa ainda pouco explorado. Contudo, se o desejado for investigar com propriedade as minúcias da rede de relações entre corrupção e participação política e as suas consequências para a democracia, novas técnicas precisam ser empregadas. Referimo-nos aos experimentos e às técnicas qualitativas, ferramentas as quais ainda somos desprovidos, mas um futuro manuseio possibilitará a ampliação dos horizontes dessa agenda de pesquisa.

\section{Referências}

BOHN, Simone. Corruption in Latin America: understanding the perception-exposure gap. Journal of Politics in Latin America, v. 4, n. 3, p. 67-95, 2012.

BONIFÁCIO, Robert; PAULINO, Rafael. Corruption and political participation in the Americas and the Caribbean. Brazilian Political Science Review, v. 9, n. 2, p. 54-80, 2015.

BOOTH, John; SELIGSON, Mitchell The legitimacy puzzle in Latin America: political support and democracy in eight nations. Cambridge: Cambridge University Press, 2009. 
BORBA, Julian. Participação política: uma revisão dos modelos de classificação. Sociedade e Estado, v. 27, n. 2, p. 263-288, 2012. BRADY, Henry. Political participation. In: ROBINSON, J. (Orgs.). Measures of political attitudes. San Diego: Academic Press, 1999. CALERA, Nicolás. Corrupción, ética y democracia: nueve tesis sobre la corrupción política. In: IBÁÑES, P.; LAPORTA, F.; ALVAREZ, S. (Orgs.). La corrupción política. Madrid: Alianza, 1989.

DOIG, Alan; MCIVOR, Stephanie. Corruption and its control in the developmental context: an analysis and selective review of the literature. Third World Quarterly, v. 20, n. 3, p. 657-676, 1999. DOIG, Alan; THEOBALD, Robin. Corruption and democratisation. London: Frank Cass, 2000.

DRASGOW, Fritz. Polychoric and polyserial correlations. In: JOHNSON, J. (Ed.). Encyclopedia of statistical sciences. New York: Wiley, 1998. v. 7.

EUBEN, J. P. Corruption. In: BALL, Terence; FARR, James; HANSON, Russell (Eds.). Political innovation and conceptual change. Cambridge: Cambridge University Press, 1989.

FIALHO, Fabrício. Participação e desigualdade política: um exercício em teoria e método. 2008. Dissertação (Mestrado em Ciência Política) - Universidade Federal de Minas Gerais, Belo Horizonte, 2008.

FILGUEIRAS, Fernando. Marcos teóricos da corrupção. In: AVRITZER, Leonardo et al. (Orgs.). Corrupção: ensaios e crítica. Belo Horizonte: Editora UFMG, 2008.

GORSUCH, R. L. Factor analysis. Hillsdale: Erlbaum, 1983.

HEIDENHEIMER, Arnold; JOHNSTON, Michael; LEVINE, Victor. Introduction to part I. In: . (Eds.). Political corruption: a handbook. New Brunswich: Transaction, 1989.

HIRSCHMAN, Albert. De consumidor a cidadão: atividades privadas e participação na vida pública. São Paulo: Brasiliense, 1983. 
HUNTER, Wendy; POWER, Timothy. Recompensando Lula: Poder Executivo, política social e as eleições brasileiras de 2006. In: MELO, Carlos; SÁEZ, Manuel (Orgs.). A democracia brasileira: balanço e perspectivas para o século 21. Belo Horizonte: Editora UFMG, 2007.

HUNTINGTON, Samuel. Political order in changing societies. New Haven: Yale University Press, 1968.

LIPSET, Seymour; LENZ, Gabriel. Corrupção, cultura e mercados. In: HARRISON, Lawrence; HUNTINGTON, Samuel (Orgs.). A cultura importa. Rio de Janeiro: Record, 2002.

MANZETTI, Luigi; WILSON, Carole. Why do corrupt governments maintain public support? In: BLAKE, Charles; MORRIS, Stephen (Eds.). Corruption and democracy in Latin America. Pittsburgh: University of Pittsburgh Press, 2009.

MILBRATH, Lester. Political participation: how and why do people get involved in politics? Chicago: Rand McNally; Company, 1965. MOISÉS, José Álvaro. A corrupção afeta a qualidade da democracia? Em Debate, v. 2, n. 5, p. 27-37, 2010.

NORRIS, Pippa. Democratic phoenix: reinventing political activism. Cambridge: Cambridge University Press, 2002.

NYE, Joseph. Corruption and political development: a cost-benefit analysis. The American Political Science Review, v. 61, n. 2, p. 419-422, 1967.

OLSSON, Sofia. Corruption and political participation: a multilevel analysis. Gothenburg: University of Gothenburg, 2014. (QoG Working Papers Series, n. 12).

PIZZORNO, Alessandro. Introducción al estudio de la participación política. In: PIZZORNO, Alessandro; KAPLAN, Marcus; CASTELLS, Manuel (Coords.). Participación y cambio social en la problemática contemporánea. Buenos Aires: Siap-Planteos, 1975.

REIS, Fábio. Mercado e utopia: teoria política e sociedade brasileira. São Paulo: Edusp, 2000.

RENNÓ, Lucio. Rewarding the corrupt? Reelection and scandal involvement in the Brazilian 2006 legislative elections. Colombia Internacional, n. 68, p. 98-107, 2008. 
RENNÓ, Lúcio; AMES, Barry. PT no purgatório: ambivalência eleitoral no primeiro turno das eleições presidenciais de 2010. Opinião Pública, v. 20, n. 1, p. 1-25, 2014.

RENNÓ, Lúcio; HOEPERS, Bruno. Voto estratégico punitivo: transferências de votos nas eleições presidências de 2006. Novos Estudos Cebrap, n. 86, p. 141-61, 2010.

ROSE-ACKERMAN, Susan. Corruption and government: causes, consequences and reform. Cambridge: Cambridge University Press, 1999.

SALINAS, Eduardo; BOOTH, John. Micro social and contextual sources of democratic attitudes in Latin America. Journal of Politics in Latin American, v. 3, n. 1, p. 29-64, 2011.

SELIGSON, Mitchell. Corruption and democratization: what is to be done? Public Integrity, v. 3, n. 3, p. 221-241, 2001. .The impact of corruption on regime legitimacy: a comparative study of four Latin American countries. Journal of Politics, v. 64, n. 2, p. 408-433, 2002.

SEÑA, Jorge. El fenómeno de la corrupción. In: IBÁÑEZ, Perfecto; LAPORTA, Francisco; ÁLVAREZ, Silvina (Coords.). La corrupción política. Madrid: Alianza, 1989.

TEORELL, Jan; TORCAL, Mariano; MONTERO, José Ramon. Political participation: mapping the terrain. In: VAN DETH, Jan; MONTERO, José; WESTHOLM, Anders. Citizenship and involvement in European democracies. New York: Routledge, 2007. VALDÉS, Ernesto. Acerca del concepto de corrupción. Claves de Razón Práctica, n. 56, p. 26-39, 1995.

VERBA, Sidney; NIE, Norman; KIM, Jae-on. Participation and political equality: a seven-nation comparison. New York: University of Chicago Press, 1987.

VERBA, Sidney; SCHLOZMAN, Kay; BRADY, Henry. Voice and equality: civic voluntarism in American politics. Cambridge: Harvard University Press, 1995.

WARREN, Mark. The meaning of corruption in democracies. In: HEYWOOD, Paul (Ed.). The Routledge international handbook on political corruption. Oxford: Routledge, 2012. 
ZÉPHYR, Dominique. Corruption and its impact on Latin American democratic stability. In: SELIGSON, Michelle (Ed.). Challenges to democracies in Latin American and the Caribean: evidence from the Americas Barometer 2006-2007. Nashville: Vanderbilt University; Washington: Usaid, 2008.

\section{Apêndice A}

Tabela A1 - Resultados de testes para predição de tolerância ao pagamento de propina a partir de perfis sociais, de 2006 a 2012 (em probabilidade)

\begin{tabular}{c|c|c|c|c|c|c|c|c}
\hline \multirow{2}{*}{} & \multicolumn{5}{|c}{2006} & \multicolumn{4}{c}{2007} \\
\cline { 2 - 9 } & CAPG & AC & APE & AP & CAPG & AC & APE & AP \\
\hline (1) NExp*NPart & $0.082^{* * *}$ & $0.089^{* * *}$ & $0.071^{* * *}$ & $0.088^{* * *}$ & $0.121^{* * *}$ & $0.100^{* * *}$ & $0.116^{* * *}$ & - \\
\hline (2) Exp*NPart & $0.343^{* * *}$ & $0.312^{* * *}$ & $0.288^{* * *}$ & $0.259^{* * *}$ & $0.365^{* * *}$ & $0.407^{* * *}$ & $0.422^{* * *}$ & - \\
\hline (3) NExp* Part & $0.088^{* * *}$ & $0.090^{* * *}$ & $0.112^{* * *}$ & $0.099^{* * *}$ & $0.115^{* * *}$ & $0.159^{* * *}$ & $0.140^{* * *}$ & - \\
\hline (4) Exp*Part & $0.219^{* *}$ & $0.282^{* * *}$ & $0.334^{* * *}$ & $0.389^{* * *}$ & $0.318^{* *}$ & $0.382^{* * *}$ & $0.398^{* * *}$ & - \\
\hline & & & & & & 2012 & \\
\hline & CAPG & AC & APE & AP & CAPG & AC & APE & AP \\
\hline (1) NExp*NPart & $0.120^{* * *}$ & $0.116^{* * *}$ & $0.106^{* * *}$ & $0.119^{* * *}$ & $0.064^{* * *}$ & $0.087^{* * *}$ & $0.064^{* * *}$ & $0.069^{* * *}$ \\
\hline (2) Exp*NPart & $0.257^{* * *}$ & $0.260^{* * *}$ & $0.203^{* * *}$ & $0.203^{* * *}$ & $0.143^{* * *}$ & $0.263^{* *}$ & $0.157^{* *}$ & $0.123^{* * *}$ \\
\hline (3) NExp*Part & $0.108^{* * *}$ & $0.111^{* * *}$ & $0.113^{* * *}$ & $0.086^{* * *}$ & $0.118^{* * *}$ & $0.052^{* *}$ & $0.087^{* * *}$ & $0.099^{* * *}$ \\
\hline (4) Exp*Part & $0.221^{* *}$ & $0.143^{* * *}$ & $0.203^{* * *}$ & $0.205^{* *}$ & $0.258^{* *}$ & 0.084 & $0.170^{* * *}$ & $0.123^{* * *}$ \\
\hline
\end{tabular}

Fonte: Dados do Barômetro das Américas, de autoria de Latin American Public Opinion Project (Lapop), disponível em: <www. LapopSurveys.org>.

Elaboração própria.

Notas: ${ }^{*}=p$ valor menor/igual a 0,10 .

** $=p$ valor menor ou igual a 0,05 .

$* * *=p$ valor menor ou igual a 0,01 .

Obs.: 1. $C A P G=$ contato com atores políticos e governamentais; $A C=$ ativismo comunitário; $A P E=$ ativismo partidário e eleitoral; $\mathrm{AP}=$ ativismo de protesto.

2. NExp*NPart = não experiência com corrupção e não participação política; Exp*NPart = experiência com corrupção e não participação política; NExp*Part = não experiência com corrupção e participação política; e Exp*Part = experiência com corrupção e participação política. 


\section{Resumo}

Investiga-se a relação entre corrupção e participação política no Brasil, a partir de análises sobre padrões de associação pertinentes e sobre a permissividade à corrupção de perfis sociais que combinam categorias de experiência com corrupção e de ativismo político. São realizadas discussões teóricas e análises empíricas, tendo como fonte exclusiva de dados o Barômetro das Américas, rodadas de dados de 2007, 2008, 2010 e de 2012. Como principais resultados, verifica-se a natureza multidimensional da participação política, segmentada em quatro modalidades distintas. Também é destaque a inequívoca associação positiva entre experiência com corrupção e engajamento político. Por fim, identifica-se uma maior permissividade à corrupção (tolerância ao pagamento de propina) entre os indivíduos que possuem experiência com corrupção, independentemente dessa característica estar ou não acompanhada de ativismo político.

Palavras-chave: corrupção; participação política; permissividade à corrupção; Brasil; Barômetro das Américas. 


\section{Abstract}

The relationship between corruption and political participation in Brazil is investigated through analysis of patterns of association and permissiveness to the corruption of social profiles that combine categories of experience with corruption and political activism. Theoretical discussions and empirical analyzes are conducted using the 2007, 2008, 2010 and 2012 rounds of the Americas Barometer as a data source. The main results are the multidimensional nature of political participation, segmented into four different modalities. The positive and unequivocal association between experience with corruption and political engagement is also highlighted. Finally, a greater permissiveness to corruption (tolerance for the payment of bribes) is identified among individuals who have experience with corruption, regardless of whether or not this characteristic is accompanied by political activism.

Keywords: corruption; political participation; corruption permissiveness; Brazil; Americas Barometer.

Recebido em 15 de setembro de 2015.

Aprovado em 16 de junho de 2016. 